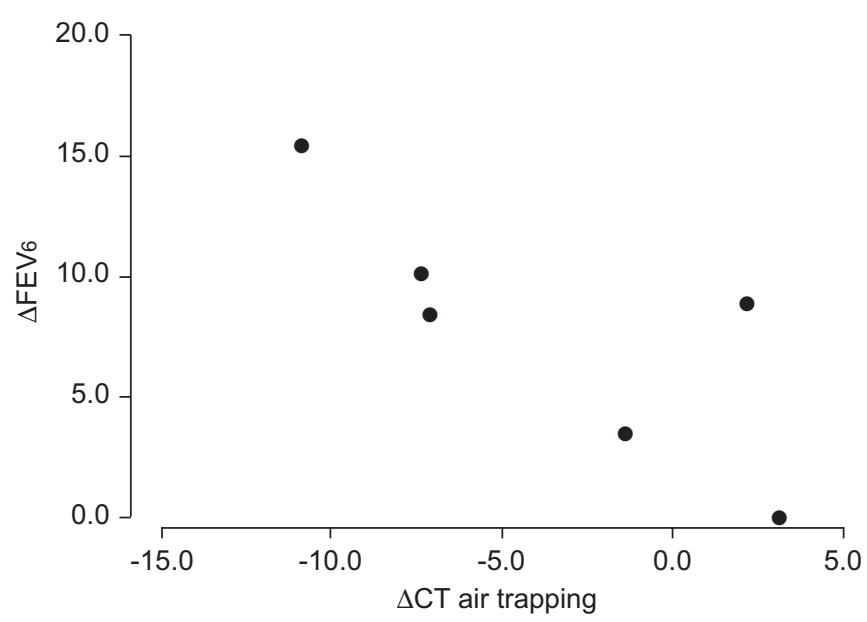

FIGURE 1. Correlation between ciclesonide-induced change (\%) in expiratory lung volume on computed tomography (CT) scan and forced expiratory volume in six seconds ( $F E V 6)$. rho $=-0.83, p=0.04$.

(375 mL) did not exceed that of the FEV3 $(500 \mathrm{~mL})$ and FEV1 $(550 \mathrm{~mL})$. This was an unexpected finding as, according to the hypothesis of J. Hansen, it indicates worsening of small airways function. However, a beneficial effect on small airways function is very likely, and this seeming paradox may be explained as follows. Improved small airways function significantly contributes to the first part of the forced expiration and thus importantly improves FEV1. As the lungs become relatively more deflated during the later phase of exhalation, a lower alveolar wall tension and a higher peripheral airway resistance lead to a relatively lower airflow and thus, relatively less improvement in FEV3 and FEV6 (in favour of FEV1). The significant correlation between ciclesonide-induced changes in FEV6 (but not FEV1 or FEV3) and air trapping on expiratory computed tomograph scan (fig. 1) is in line with this explanation.

We thank our colleagues J. Hansen for making us aware of this seeming paradox.

J. Cohen, N.R. Douma, N.H.T. ten Hacken and D.S. Postma Dept of Pulmonology, University Medical Center Groningen, University of Groningen, Groningen, The Netherlands.

\section{STATEMENT OF INTEREST}

A statement of interest for D.S. Postma can be found at www.erj.ersjournals.com/misc/statements.shtml

\section{REFERENCES}

1 Kainu A, Lindqvist A, Sarna S, Sovijärvi A. Intra-session repeatability of FET and FEV6 in the general population. Clin Physiol Funct Imaging 2008; 28: 196-201.

2 Bellia V, Sorino C, Catalano F, et al. Validation of FEV6 in the elderly: correlates of performance and repeatability. Thorax 2008; 63: 60-66.

3 Cohen J, Douma WR, ten Hacken NHT, Vonk JM, Oudkerk M, Postma DS. Ciclesonide improves measures of small airway involvement in asthma. Eur Respir J 2008; 31: 1213-1220.

\title{
A possible role for Epstein-Barr virus infection in COPD?
}

\section{To the Editors:}

We read with interest the paper by McMANus et al. [1], which appeared in a recent issue of the European Respiratory Journal. It is indeed tempting to suggest a role for latent viral infections in the development of chronic obstructive pulmonary disease. Epstein-Barr virus (EBV) infection has been associated with several medical conditions, as pointed out by those authors. However, relatively little is known about the role of EBV in chronic pulmonary conditions. Our research group focuses on the role of EBV infection in pulmonary conditions such as pleural effusion [2] and unexplained parenchymal disease [3].

We would like to make some comments on the study by McMANus et al. [1]. The authors did not establish the serostatus of the patients and controls included in the study. This could be of importance because the control group had a significantly lower age compared to the study group. The proportion of subjects with a positive EBV serostatus is positively associated with age.

Another point of concern is the possible contamination of sputum samples with EBV DNA present in saliva. EBV loads in saliva can be very high [4]. Even though sputum was separated from saliva it could be helpful to measure the EBV load in sputum and determine the correlation between saliva and sputum results for EBV PCR.

A third possible confounder could be the presence of B-cells in sputum. MCMANUs et al. [1] argue that EBV DNA PCR is indicative of viral replication; however, the PCR used cannot differentiate between DNA derived from active viral replication or latent infection. B-cells are known to harbour EBV in the latency phase. Determination of the number of B-cells in the sputum could have revealed whether these cells contribute to the relatively high levels of EBV in the study group. 
A final concern is that McMANUs et al. [1] do not show whether spontaneously produced sputa and induced sputa were equally derived across all groups. Induction with hypertonic saline could dilute the Epstein-Barr virus DNA count. We are concerned that, particularly in the control group, induction of sputum production was needed.

\section{A.W.J. Bossink*, M. Deege ${ }^{\#}$ and S.F.T. Thijsen ${ }^{\#}$}

*Depts of Pulmonology and Tuberculosis, and "Medical Microbiology and Immunology, Diakonessenhuis Utrecht, Utrecht, The Netherlands.

\section{STATEMENT OF INTEREST}

None declared.

\section{REFERENCES}

1 McManus TE, Marley A-M, Baxter N, et al. High levels of Epstein-Barr virus in COPD. Eur Respir J 2008; 31: 1221-1226.

2 Thijsen SFT, Luderer R, van Gorp JMH, Oudejans SJG, Bossink AWJ. A possible role for Epstein-Barr virus in the pathogenesis of pleural effusion. Eur Respir J 2005; 26: 662-666.

3 Deege D, Thijsen T, Luderer R, et al. EBV and CMV as possible pathogens in patients presenting with interstitial lung disease. Eur Respir J 2006; 28: Suppl. 50, 154s.

4 van Kooy B, Thijsen SFT, Meijer E, et al. Sequence analysis of EBV DNA isolated from mouth washings and PBMC's of healthy individuals and blood of EBV-LPD patients. J Clin Virol 2003; 28: 85-92.

DOI: $10.1183 / 09031936.00096308$

\section{To the Editors:}

The recent paper by McMANus et al. [1] linking high levels of Epstein-Barr virus (EBV) to chronic obstructive pulmonary disease (COPD) is important as it appears to provide additional evidence supporting a connection between low serum 25-hydroxyvitamin D (calcidiol) and risk of COPD, and thus a possible simple way to reduce the risk of COPD. In an observational study, low pulmonary function was found to correlate with low serum calcidiol levels [2]. Statistically significant higher values of forced expiratory volume in one second (FEV1) were found in: both sexes; those $>60$ yrs of age; White and Black subjects; subjects of any smoking status; subjects with a lack of asthma; those with or without bronchitis or emphysema.

There is additional support for a vitamin D-COPD link. Indeed, frequent cases of acute bronchitis increase the risk of COPD [3]. Respiratory syncytial virus (RSV) is an important risk factor for acute bronchitis. Solar ultraviolet (UV)B has been found to explain some of the seasonal and latitudinal variation in RSV activity. In a recent study, solar UVB explained 13\% of the RSV activity in Miami (FL, USA), 5\% in Buffalo (NY, USA) and $0.6 \%$ in Winnipeg (MB, Canada) [4]. The relevant action of vitamin D is the induction of human cathelicidin, LL-37 [5]. LL-37 is an important component of the innate immune system and vitamin D supplementation was demonstrated to reduce the risk of viral infections in a post hoc analysis of a randomised controlled trial.
Black postmenopausal women living in the state of New York (USA) had one-tenth the incidence rate of seasonal influenza and common cold when taking 2,000 IU $\cdot$ day $^{-1}$ of vitamin D3 compared with those taking a placebo; those taking $800 \mathrm{IU} \cdot \mathrm{day}^{-1}$ had $40 \%$ the incidence rate of those taking a placebo [6].

There is growing evidence that EBV is a virus that is subject to the effects of vitamin D and LL-37. EBV is an important risk factor for multiple sclerosis [7]. The prevalence of multiple sclerosis increases with latitude in a manner related to wintertime solar UVB and vitamin D production. In the USA, those living at $28^{\circ} \mathrm{N}$ had $31 \%$ as much prevalence of multiple sclerosis as those living at $48^{\circ} \mathrm{N}$, based on a study of veterans at the time of enlistment into World War II and the Korean conflict [8]. Summertime solar UVB doses are much higher from the Rocky Mountains (USA) to the west, than from the east of the Rocky Mountains at the same latitude due to higher surface elevation and thinner stratospheric ozone layer, and do not explain the observed prevalence findings. Multiple sclerosis is often preceded by infectious mononucleosis (IM) [9], and EBV is a risk factor for IM. Both IM and Hodgkin's lymphoma, another disease linked to EBV, have a peak incidence rate in spring, a time when calcidiol levels are lowest, amongst those $<40$ yrs of age [10].

It would therefore be worthwhile recommending increased serum calcidiol levels at the population level, especially in winter, in order to reduce the risk of chronic obstructive pulmonary disease. Those with chronic obstructive pulmonary disease may also be likely to benefit from increasing their serum calcidiol levels.

\section{W.B. Grant}

Sunlight, Nutrition, and Health Research Center (SUNARC), San Francisco, CA, USA.

\section{STATEMENT OF INTEREST}

None declared.

\section{REFERENCES}

1 McManus TE, Marley A-M, Baxter N, et al. High levels of Epstein-Barr virus in COPD. Eur Respir J 2008; 31: 1221-1226.

2 Black PN, Scragg R. Relationship between serum 25hydroxyvitamin D and pulmonary function in the third national health and nutrition examination survey. Chest 2005; 128: 3792-3798.

3 Piperno D, Bart F, Serrier P, Zureik M, Finkielsztejn L. [General practice patients at risk of chronic obstructive pulmonary disease: epidemiologic survey of 3,411 patients]. Presse Med 2005; 34: 1617-1622.

4 Yusuf S, Piedimonte G, Auais A, et al. The relationship of meteorological conditions to the epidemic activity of respiratory syncytial virus. Epidemiol Infect 2007; 135: 1077-1090.

5 Liu PT, Stenger S, Tang DH, Modlin RL. Cutting edge: vitamin D-mediated human antimicrobial activity against Mycobacterium tuberculosis is dependent on the induction of cathelicidin. J Immunol 2007; 179: 2060-2063.

6 Aloia JF, Li-Ng M. Re: epidemic influenza and vitamin D. Epidemiol Infect 2007; 135: 1095-1096; author reply 1097-1098. 